\title{
Producing GM-CSF: a unique T helper subset?
}

\author{
Cell Research (2014) 24:1379-1380. doi:10.1038/cr.2014.155; published online 21 November 2014
}

GM-CSF-producing helper $T$ cells have previously been identified to serve a nonredundant function in the initiation of autoimmune inflammation. An article by Sheng et al. recently published by Cell Research now suggests that the differentiation program of GM-CSF-producing cells from naïve $\mathrm{CD}^{+} \mathrm{T}$ cells is distinct from that of Th1 and Th17 cells, and is regulated by the IL-7-STAT5 axis.

Interferon- $\gamma(\mathrm{IFN}-\gamma)$-producing $\mathrm{T}$ helper type 1 (Th1) cells and interleukin 17 (IL-17)-producing $\mathrm{T}$ helper (Th17) cells have been shown to drive chronic inflammatory diseases. However, in the animal model of multiple sclerosis, experimental autoimmune encephalomyelitis (EAE), IFN- $\gamma$, the Th1-inducing cytokine IL-12 and Th17-associated cytokines such as IL17A, IL-17F, IL-21 and IL-22 have all been shown to be dispensable for the development of EAE. It was not until 2011, when the pathogenicity of Th17 cells has been associated with their production of granulocyte-macrophage colony-stimulating factor (GM-CSF) [1, 2]. GM-CSF is a potent proinflammatory cytokine that is responsible for the recruitment, maturation and activation of innate immune cells. In this regard, GM-CSF production by $T$ cells has been associated with several autoimmune diseases, such as multiple sclerosis, rheumatoid arthritis and myocarditis.

The groups of Becher and Rostami demonstrated that IL-1- and IL-23-induced production of GM-CSF by CNSinfiltrating $\mathrm{CD}^{+} \mathrm{T}$ cells is essential for the induction of EAE $[1,2]$. These studies also demonstrated that IL-1 and IL-23 drive the differentiation of
Th1 and Th17 effector cells into highly pathogenic GM-CSF-producing $\mathrm{CD}^{+}$ $\mathrm{T}$ cells (Figure 1 ). GM-CSF thereby exerts a nonredundant function in EAE pathogenicity, regardless of the polarization pattern of $\mathrm{CD}^{+}$effector $\mathrm{T}$ cells. Although IL-23 promotes GM-CSF production in Th17 cells, the two studies have discordant results about the role of ROR $\gamma t$ in driving GM-CSF production. The key questions that have not yet been answered by these studies are, whether naïve $\mathrm{CD} 4^{+} \mathrm{T}$ cells can directly differentiate into GM-CSF-producing effector $\mathrm{CD}^{+} \mathrm{T}$ cells, whether these effector $\mathrm{CD}^{+} \mathrm{T}$ cells represent a unique $T$ helper cell lineage and which signaling pathways might regulate this $\mathrm{T}$ cell differentiation.

In a recent paper published in Cell Research, Sheng et al. [3] demonstrate that conditional Stat5-knockout mice (Stat $5^{\text {flox/flox }} \mathrm{Cd} 4-\mathrm{Cre}^{+}$mice) are resistant to EAE development. Although, the role of STAT5 in T cell-mediated autoimmune diseases has not been well characterized, this result is interesting and surprising since STAT5-mediated signaling is essential for regulatory $\mathrm{T}$ cell (Treg) development and inhibits the differentiation of Th17 cells $[4,5]$.

To determine whether Stat5-deficient $\mathrm{CD}^{+} \mathrm{T}$ cells have an intrinsic encephalitogenic defect, Stat $5^{-/-} \mathrm{CD} 4^{+}$ $\mathrm{T}$ cells were transferred into $\mathrm{Rag}^{-/-}$ mice and EAE was induced by immunization with $\mathrm{MOG}_{35-55}$ and Complete Freund's Adjuvant (CFA). Rag $2^{-/}$mice reconstituted with Stat $^{-/-} \mathrm{CD} 4^{+} \mathrm{T}$ cells had significantly reduced EAE disease incidence and severity. Although there were fewer CNS-infiltrating $\mathrm{CD}^{+} \mathrm{T}$ cells at the peak of the disease, the resistance to EAE was not due to decreased homing to or survival in the CNS. The percentage of Th1 and Th17 cells among CNS-infiltrating $\mathrm{CD}^{+}$ $\mathrm{T}$ cells was also comparable between Rag2 $2^{-/}$mice that were reconstituted with Stat $^{+/+}$or Stat $^{-/-}$CD4 ${ }^{+}$T cells. However, $\mathrm{MOG}_{35-55^{-}}$-specific Stat $5^{-/}$ $\mathrm{CD}^{+} \mathrm{T}$ cells produced significantly less GM-CSF. Further experiments showed that IL-7-mediated STAT5 signaling promoted the expression of GM-CSF in both naïve and effector $\mathrm{CD} 4^{+} \mathrm{T}$ cells, and antibody-mediated blockage of IL-7 signaling resulted in decreased GM-CSF expression in CNS-infiltrating $\mathrm{CD}^{+} \mathrm{T}$ cells. Chromatin immunoprecipitation (ChIP) analysis showed that IL-7-activated STAT5 directly bound to promoter regions of the $C s f 2$ gene, which encodes GM-CSF.

These results are in agreement with a recent study showing that STAT5mediated signaling induced GM-CSF expression in human naïve and memory $\mathrm{CD}^{+} \mathrm{T}$ cells, whereas STAT3 signaling blocked it [6]. In fact, dysregulation of the IL-7/IL-7R axis has long been implicated in autoimmune diseases, such as type 1 diabetes, multiple sclerosis and rheumatoid arthritis [7, 8]. Thus, the results from Sheng et al. may now provide a mechanistic link between IL-7/STAT5-mediated signaling and $\mathrm{T}$ helper cell-mediated pathogenicity.

To characterize whether GM-CSFproducing $\mathrm{CD}^{+} \mathrm{T}$ cells represent a unique $\mathrm{T}$ helper cell lineage, Sheng et $a l$. performed microarray analysis and identified 211 genes that were expressed in $\mathrm{GM}^{-\mathrm{CSF}^{+}}$Th cells, but not in Th1, Th17 or naïve $\mathrm{CD}^{+} \mathrm{T}$ cells. As GMCSF-producing $\mathrm{CD}^{+} \mathrm{T}$ cells did not 


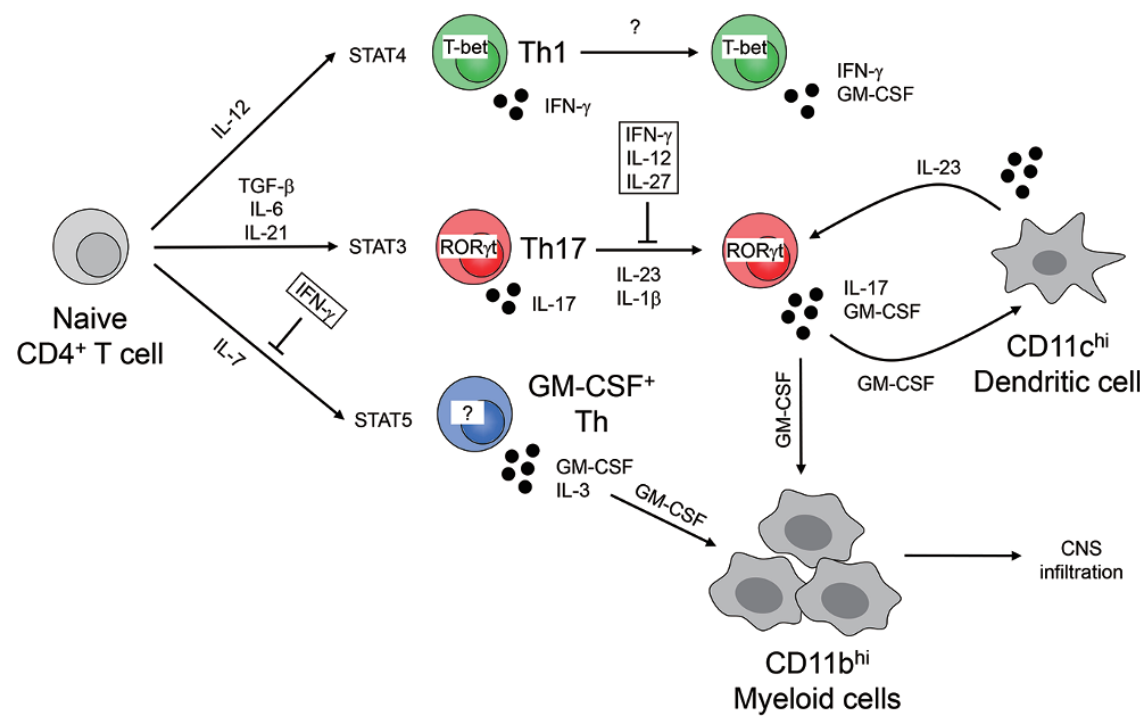

Figure 1 The role of $\mathrm{T}$ helper cell subsets and the cytokine environment in driving autoimmune inflammation.

express the transcription factors ROR $\gamma \mathrm{t}$ and T-bet, Sheng et al. hypothesize that $\mathrm{GM}_{-} \mathrm{CSF}^{+}$Th cells may represent a unique Th cell lineage. This is an intriguing hypothesis that will require further investigation. In particular, which transcription factor regulates GM-CSF- producing Th cells, how plastic are $\mathrm{GM}^{-\mathrm{CSF}^{+}}$Th cells in vitro and in vivo, and are other STAT5-inducing cytokines or growth factors (e.g., thymic stromal lymphopoietin (TSLP), IL-3, IL-5, IL9, IL-15, GM-CSF, growth hormones, etc.) involved in the development of
$\mathrm{GM}-\mathrm{CSF}^{+}$Th cells [9]?

Dietmar Herndler-Brandstetter ${ }^{1}$, Richard A Flavell ${ }^{1,2}$

${ }^{1}$ Department of Immunobiology, ${ }^{2}$ Howard Hughes Medical Institute, Yale University School of Medicine, New Haven, CT 06520, USA

Correspondence: Richard A Flavell E-mail: Richard.flavell@yale.edu

\section{References}

1 Codarri L, Gyulveszi G, Tosevski V, et al. Nat Immunol 2011; 12:560-567.

2 El-Behi M, Ciric B, Dai H, et al. Nat Immunol 2011; 12:568-575.

3 Sheng W, Yang F, Zhou Y, et al. Cell Res 2014; 24:1387-1402.

4 Malek TR, Yu A, Vincek V, et al. Immunity 2002; 17:167-178.

5 Laurence A, Tato CM, Davidson TS, et al. Immunity 2007; 26:371-381.

6 Noster R, Riedel R, Mashreghi MF, et al. Sci Transl Med 2014; 6:241ra280.

7 Ribeiro D, Melao A, Barata JT. Adv Biol Regul 2013; 53:211-222.

8 Lee LF, Logronio K, Tu GH, et al. Proc Natl Acad Sci USA 2012; 109:12674-12679.

9 O'Shea JJ, Paul WE. Science 2010; 327:10981102. 